\title{
Bioenergetics of contracting skeletal muscle after partial reduction of blood flow
}

\author{
MICHAEL C. HOGAN, ${ }^{1}$ L. BRUCE GLADDEN, ${ }^{2}$ BRUNO GRASSI, ${ }^{3}$ \\ CREED M. STARY, ${ }^{1}$ AND MICHELE SAMAJ A ${ }^{4}$ \\ ${ }^{1}$ Department of Medicine, University of California, San Diego, La J olla, \\ California 92093-0623; '2Department of Health and Human Performance, Auburn \\ University, Auburn, Alabama 36849-5323; 3 Istituto di Tecnologie Biomediche \\ Avanzate, Consiglio Nazi onale delle Ricerche, and ${ }^{4}$ Di partimento di Scienze \\ e Tecnol ogie Biomediche, Universitá di Milano, I-20090 Segrate, Milan, Italy
}

\begin{abstract}
Hogan, Michael C., L. Bruce Gladden, Bruno Grassi, Creed M. Stary, and Michele Samaja. Bioenergetics of contracting skeletal muscle after partial reduction of blood flow. J . Appl. Physiol. 84(6): 1882-1888, 1998.-The purpose of this study was to examine the bioenergetics and regulation of $\mathrm{O}_{2}$ uptake $\left(\mathrm{VO}_{2}\right)$ and force production in contracting muscle when blood flow was moderately reduced during a steadystate contractile period. Canine gastrocnemius muscle $(n=5)$ was isolated, and 3-min stimulation periods of isometric, tetanic contractions were elicited sequentially at rates of $0.25,0.33$, and 0.5 contractions/s $(\mathrm{Hz})$ immediately followed by a reduction of blood flow [ischemic (I) condition] to $46 \pm 3 \%$ of the value obtained at $0.5 \mathrm{~Hz}$ with normal blood flow. The $\mathrm{VO}_{2}$ of the contracting muscle was significantly $(\mathrm{P}<0.05)$ reduced during the $\mathrm{I}$ condition $[6.5 \pm 0.8$ (SE) $\mathrm{ml} \cdot 100$ $\mathrm{g}^{-1} \cdot \mathrm{min}^{-1}$ ] compared with the same stimulation frequency with normal flow (11.2 $\left.\pm 1.5 \mathrm{ml} \cdot 100 \mathrm{~g}^{-1} \cdot \mathrm{min}^{-1}\right)$, as was the tension-time index $\left(79 \pm .12\right.$ vs. $123 \pm 22 \mathrm{~N} \cdot \mathrm{g}^{-1} \cdot \mathrm{min}^{-1}$, respectively). The ratio of $\mathrm{VO}_{2}$ to tension-time index remained constant throughout all contraction periods. Muscle phosphocreatine concentration, ATP concentration, and lactate efflux were not significantly different during the I condition compared with the $0.5-\mathrm{Hz}$ condition with normal blood flow. However, at comparable rates of $\mathrm{V}_{2}$ and tension-time index, muscle phosphocreatine concentration and ATP concentration were significantly less during the I condition compared with normal-flow conditions. These results demonstrate that, in this highly oxidative muscle, the normal balance of $\mathrm{O}_{2}$ supply to force output was maintained during moderate ischemia by downregulation of force production. In addition, 1 ) the minimal disruption in intracellular homeostasis after the initiation of ischemia was likely a result of steady-state metabolic conditions having already been activated, and 2) the difference in intracellular conditions at comparable rates of $\mathrm{VO}_{2}$ and tension-time index between the normal flow and I condition may have been due to altered intracellular $\mathrm{O}_{2}$ tension.
\end{abstract}

oxygen uptake; exercise; adenosine 5'-triphosphate; lactate; lactic acid; mitochondrial respiration; phosphocreatine; glycolysis

IN MOST CONDITIONS of steady-state muscle contractile activity, ATP production related to the $\mathrm{O}_{2}$ uptake $\left(\mathrm{VO}_{2}\right)$ of the contracting muscle is tightly coupled to the rate of ATP demand so that steady-state energy expenditure is maintained with minimal change in intracellular ATP concentration ([ATP]; e.g., see Ref. 12). When the supply of $\mathrm{O}_{2}$ (and oxidative substrate) to the mitochondria is sufficient, increases in myofibril ATPase activity with higher energy demands result in changes in the concentration of several signals [phosphocreatine $(\mathrm{PCr})$, ADP, $P_{i}$, etc.] that are thought to regulate mitochondrial respiration $(4,5,18,20,22)$ in a manner that causes oxidative phosphorylation to increase proportionally with ATPase activity. However, when the supply of $\mathrm{O}_{2}$ to the mitochondria is insufficient, thetight coupling between the ATP demand of the myofibril ATPases and the ATP supply by mitochondrial respiration may be disrupted, and an increased reliance on ATP regeneration derived from substrate-level phosphorylation ( $\mathrm{PCr}$ hydrolysis and anaerobic glycolysis) may ensue. The result of prol onged mitochondrial $\mathrm{O}_{2}$ limitation can bea downregulation of ATPase activity, thereby reducing force development, so that ATP demand does not exceed the reduced ATP production.

When mitochondrial $\mathrm{O}_{2}$ limitation is caused by re duced $\mathrm{O}_{2}$ availability due to inadequate blood flow (ischemia), there is evidence that the manner in which the blood flow reduction is imposed may influence muscle metabolism and the degree of impairment of contractile function $(12,16,17,31)$. Timmons et al. (28-30) recently demonstrated that substrateavailability through the pyruvate dehydrogenase complex (PDC) for carbohydrate oxidation in the tricarboxylic cyclecan affect subsequent muscle performance during moderate ischemia. These investigators (30) demonstrated that having the PDC enzyme fully activated at the onset of an ischemic contractile period resulted in significantly less PCr hydrolysis and lactate accumulation and subsequently less fatigue compared with the same ischemic blood flow reduction with PDC starting from the normal resting deactivated state.

Although there has been extensive investigation of the coupling of cell respiration to force production under conditions of adequate $\mathrm{O}_{2}$ availability to the mitochondria, there has been substantially less research done concerning the manner in which muscle reestablishes steady-state conditions when $\mathrm{O}_{2}$ availability becomes limiting. The purpose of the present study was to investigate the control of coupling of muscle force output to the rate of mitochondrial respiration when the $\mathrm{O}_{2}$ supply to the mitochondria was insufficient to meet the energy demand. In addition, wetested the hypothesis that having the muscle in an aerobic steady state of contractile activity with normal blood flow, in which the PDC and other regulatory enzymes were fully activated, would minimize the metabolic disruption when partial ischemia was induced. 


\section{METHODS}

Five adult mongrel dogs of either sex with a weight range of 12- $19 \mathrm{~kg}$ were anesthetized with pentobarbital sodium (30 $\mathrm{mg} / \mathrm{kg}$ ). Maintenance doses were given as required. The dogs were intubated with cuffed endotracheal tubes, and ventilation was maintained with a Harvard 613 ventilator at a rate that achieved normal values of arterial $\mathrm{PO}_{2}$ and $\mathrm{PCO}_{2}$. E sophageal temperature was maintained near $37^{\circ} \mathrm{C}$ by the use of heating pads. The animals were given heparin at a dosage of $1,500 \mathrm{U} / \mathrm{kg}$ after the surgery.

Surgical preparation. The left gastrocnemius-flexor digitorum superficialis muscle complex (for convenience referred to as gastrocnemius) was isolated as described previously (15). Briefly, the muscle was isolated from nearby muscle groups, and all vessels draining into the popliteal vein except for those from the gastrocnemius were ligated to isolate the venous outflow from the gastrocnemius. The arterial circulation to the gastrocnemius was isolated by ligating all vessels from the femoral and popliteal artery that did not enter the gastrocnemius. The left popliteal vein was cannulated, and the venous outflow from the isolated muscle was returned to the animal via a jugular catheter.

Theright femoral artery was catheterized for arterial blood sampling. This catheter was connected to the left femoral artery so that the isolated muscle was perfused by blood from this contralateral artery. Perfusion was accomplished either directly from the contralateral (systemic pressure, selfperfused) or via a Sigmamotor pump to control flow. All experimental conditions were conducted with blood flow perfusion controlled by the pump. A pressure transducer in this line at the head of the muscle constantly monitored perfusion pressure. A carotid artery was also catheterized to monitor systemic blood pressure. Theleft sciatic nerve, which innervates the gastrocnemius, was doubly ligated and cut between ties. To prevent cooling and drying, all exposed tissues were covered with saline-soaked gauze and with a sheet of Saran. After the muscle was surgically isolated, the Achilles tendon was attached to an isometric myograph to measure force devel opment.

The hindlimb was fixed at the knee and ankle and attached to the myograph with struts to minimize movement. Weights were used at the end of each experiment to calibrate the force myograph. The isometric force developed by each muscle was normalized to the weight of that muscle. Before each contraction period, the resting muscle was passively stretched until the force produced by a single tetanic contraction was maximal.

Experimental protocol. Isometric muscle contractions (tetanic) were elicited by stimulation of the sciatic nerve with square-wave impulses (6-8 V) of 0.2-ms duration at a rate of 50 impulses/s, with this train of impulses lasting $0.2 \mathrm{~s}$ (so 10 impulses during each contraction). Each muscle $(n=5)$ was stimulated to contract in a consecutive manner for 3-min at each of threestimulation frequencies: one contraction every 4 $(0.25 \mathrm{~Hz}), 3(0.33 \mathrm{~Hz})$, and $2(0.5 \mathrm{~Hz}) \mathrm{s}$. Muscle blood flow for these three stimulation patterns was set at a rate that kept muscle perfusion pressure at $\sim 130 \mathrm{mmHg}$. After $3 \mathrm{~min}$ of the $0.5-\mathrm{Hz}$ stimulation (highest contractile intensity; 60-70\% of the peak $\mathrm{V}_{2}$ ), the blood flow was immediately reduced by $\sim 50 \%$ so that $\mathrm{O}_{2}$ delivery was reduced $50 \%$ [ischemia (I)]. Muscle force development was then allowed to stabilize at a new steady state, which typically took 3-4 min.

Measurements. Arterial blood samples from the arterial line entering the muscle and venous samples from the left popliteal vein as close to the gastrocnemius as possible were drawn anaerobically at the end of each rest period, at the end of each 3-min contraction period, and at the end of the moderate-ischemia period. These samples were kept on ice for the brief time before measurement. Venous blood flow measurements were made at the same time the blood samples were drawn by timed blood collections into a graduated cylinder. Barbee et al. (1), using muscle contractions similar to those used in this investigation, determined that a steadystate flow and $\mathrm{VO}_{2}$ had been achieved by the end of $2 \mathrm{~min}$.

Muscle biopsies were obtained immediately after the blood measurements were taken. These biopsies were obtained by using the Bergstrom needle-biopsy technique (3) and frozen in liquid $\mathrm{N}_{2}$ within 2-4 s. In all, five biopsies were obtained from each muscle from separate randomly selected sites (1 at rest, 1 at the end of the 3 different stimulation periods, and 1 at the end of the I condition). The dog gastrocnemius is composed of only high-oxidative fibers (type I and Ila; Ref. 19), with $\sim 50 \%$ being slow oxidative (type I), so there should be little variability in fiber type distribution throughout the more superficial areas of the muscle where biopsy sampling occurred. The muscle was removed and weighed at the end of each experiment.

Muscle force development was measured from the chart recordings and reported as newtons per 100 grams of muscle mass. Muscle fatigue was calculated as the decline in muscle force development with time and was reported as the tension development at that time as a percentage of the initial tension development for that condition. The tension-time index was used as an indication of ATP demand and was calculated as isometric force produced for a fixed amount of time (newtons of force developed per gram of muscle per minute).

Blood lactate concentrations were determined (after red cell lysing) from the arterial and venous samples by using a Yell ow Springs I nstruments $23 \mathrm{~L}$ blood lactate analyzer. Blood $\mathrm{PO}_{2}, \mathrm{PCO}_{2}$, and $\mathrm{pH}$ were measured within 5-8 min with a blood-gas analyzer [model 813, Instrumentation Laboratory (IL)] at $37^{\circ} \mathrm{C}$ while hemogl obin concentration ([Hb]), percent $\mathrm{O}_{2}$ saturation, percent $\mathrm{CO}$ saturation, and $\mathrm{O}_{2}$ concentration $\left(\left[\mathrm{O}_{2}\right]\right)$ were measured with an IL 282 CO-oximeter. These instruments were calibrated before each experiment and often throughout each experiment. The Fick principle was used to cal culate muscle $\mathrm{VO}_{2}$ and lactate efflux.

Tissue samples (40-70 mg) were deproteinized in $0.5 \mathrm{M}$ perchloric acid and neutralized. After centrifugation, the supernatant of each sample was analyzed for [ATP], $\mathrm{PCr}$ concentration ([PCr]), and creatine concentration ([creatine]) by high-performance liquid chromatography (23). The values of [ATP] and [PCr] were normalized to the total [creatine] $([\mathrm{Cr}]+[\mathrm{PCr}])$ in each individual sample. Total [creatine] has been shown to be an excellent normalization parameter for skeletal muscle because of its constancy at different work intensities $(4,5)$. All values of [PCr] and [ATP] are reported as a percentage of the resting values.

Statistics. Repeated-measures analysis of variance was used for the statistical analysis. Values are expressed as means \pm SE. In all statistical analyses, the 0.05 level of significance was used.

\section{RESULTS}

Mean weight of the gastrocnemius muscles $(n=5)$ removed after the end of the experiment was $63 \pm 3$ (SE) $\mathrm{g}$.

The arterial $\mathrm{PO}_{2}\left(95 \pm 7\right.$ Torr), arterial $\mathrm{PCO}_{2}(45 \pm 2$ Torr), arterial $\mathrm{pH}(7.36 \pm 0.02)$, arterial $\mathrm{HCO}_{3}^{-}$concentration (26 $\pm 2 \mathrm{mM})$, arterial [Hb] $(15.1 \pm 0.6 \mathrm{~g} / 100 \mathrm{ml})$, and arterial $\left[\mathrm{O}_{2}\right](17.1 \pm 0.8 \mathrm{ml} / 100 \mathrm{ml})$ were similar 
among muscles and did not change throughout the experimental period. Perfusion pressure to the contracting muscle was kept constant at $130 \pm 8 \mathrm{mmHg}$ for the three contraction periods $(0.25,0.33$, and $0.5 \mathrm{~Hz})$ with normal blood flow. Muscle blood flow increased in a linear fashion with increasing stimulation frequency (significant increase with each change) and was reduced significantly (to $46 \%$ of the value obtained at 0.5 $\mathrm{Hz}$ with normal flow; $\mathrm{P}<0.05)$ during the I condition, as shown in Fig. 1A. Because $[\mathrm{Hb}]$ and arterial $\mathrm{PO}_{2}$ did
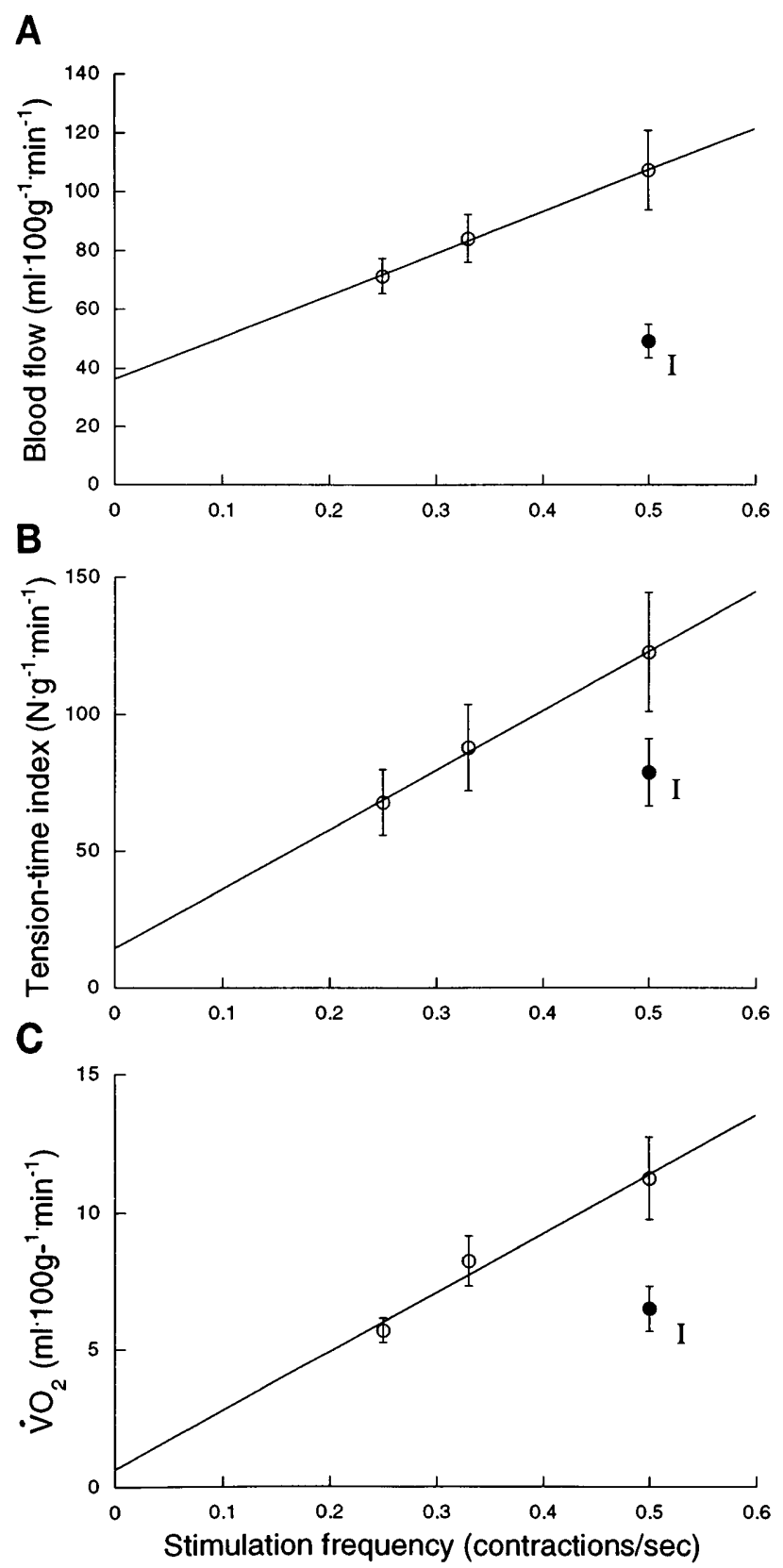

Fig. 1. Relationship between muscle blood flow (A), tension-time index (index of work performed by muscle; calculated as isometric force produced for a fixed amount of time; $\mathrm{B})$, muscle $\mathrm{O}_{2}$ uptake $\left(\mathrm{V}_{2}\right.$; $C)$, and stimulation frequency for the 3 contraction periods at which blood flow was normal $(\mathrm{O})$ and the ischemic $(\mathrm{I} ; \bullet)$ contraction period. Values are means $\pm \mathrm{SE}$. Correlation lines are drawn from regression analysis (best fit) by using the 3 stimulation patterns with unre stricted blood flow. not change, $\mathrm{O}_{2}$ delivery to the muscle was proportional to muscle blood flow and thereby mirrored the blood flow changes seen in Fig. $1\left(\mathrm{O}_{2}\right.$ delivery $=11.9,14.2$, 18.0, and $8.3 \mathrm{ml} \mathrm{O}_{2} \cdot 100 \mathrm{~g}^{-1} \cdot \mathrm{min}^{-1}$ for the $0.25-\mathrm{Hz}$, $0.33-\mathrm{Hz}, 0.5-\mathrm{Hz}$, and I conditions, respectively).

As illustrated in Fig. 1B, the tension-time index (index of muscle force production for a fixed time period) increased linearly for the three stimulation patterns with normal blood flow (significant increase with each change) but was significantly reduced from the $0.5-\mathrm{Hz}$ stimulation period during the I condition to a level not significantly different from that during the $0.25-\mathrm{Hz}$ stimulation period. The peak developed force did not fall as the stimulation frequency was increased from 0.25 to 0.33 to $0.5 \mathrm{~Hz}$; peak developed force only fell (to $65 \%$ of normal) when the I condition was imposed. $\mathrm{VO}_{2}$ changes are shown in Fig. $1 \mathrm{C}$ and were similar to the changes seen in the tension-time index (Fig. 1B), with $\mathrm{VO}_{2}$ increasing significantly with each stimulation frequency and then being reduced significantly (compared with the normal flow $0.5-\mathrm{Hz}$ stimulation period) to a level not significantly different from the $0.25-\mathrm{Hz}$ stimulation period.

The relationship of $\mathrm{VO}_{2}$ to muscle blood flow is illustrated in Fig. 2. $\mathrm{VO}_{2}$ was maintained in the I condition similar to the $0.25-\mathrm{Hz}$ stimulation condition, even though blood flow was significantly less $(\mathrm{P}<.0 .05)$, by a significantly higher $\mathrm{O}_{2}$ extraction ratio $\left(\mathrm{VO}_{2} / \mathrm{O}_{2}\right.$ delivery). In the $0.25-\mathrm{Hz}$ condition, $48 \%$ of the $\mathrm{O}_{2}$ delivered was utilized by the contracting muscle compared with $78 \%$ in the I condition. Figure 3 shows the $\mathrm{VO}_{2}$ /tension-time index relationship, which demonstrates that the $\mathrm{VO}_{2}$ and tension-time index fell proportionally during the I condition. In fact, there was no significant difference in the $\mathrm{VO}_{2} /$ tension-time index among the three normal flow conditions $(1.04 \pm 0.09 \mu \mathrm{l}$ $\left.\mathrm{O}_{2} / \mathrm{N}\right)$ and the l condition $\left(1.00 \pm 0.15 \mu \mathrm{l} \mathrm{O}_{2} / \mathrm{N}\right)$.

Figures 4 and 5 illustrate the relationship of muscle [ATP] and [PCr] to the tension-time index and $\mathrm{V}_{2}$, respectively. Muscle [ATP] was significantly reduced bel ow resting values during each stimulation frequency but was not significantly different among the three stimulation conditions with normal blood flow. During the I condition, muscle [ATP] was not significantly different compared with the $0.5-\mathrm{Hz}$ condition with normal blood flow but was significantly less than that measured during the $0.25-\mathrm{Hz}$ stimulation period. Muscle [PCr] was significantly less during all stimulation paradigms compared with rest and it fell significantly from the $0.25-\mathrm{Hz}$ treatment to the $0.33-\mathrm{Hz}$ treatment, but it was not significantly different between the 0.33and $0.5-\mathrm{Hz}$ stimulation periods with normal blood flow. During the I condition, muscle [PCr] was not significantly reduced compared with the $0.33-$ and $0.5-\mathrm{Hz}$ conditions with normal flow but was significantly reduced compared with the $0.25-\mathrm{Hz}$ stimulation period. Lactate output by the muscle was not significantly different among the three normal blood flow conditions and the I condition $(6 \pm 6,7 \pm 10,20 \pm 13,26 \pm 13$ $\mu \mathrm{mol} \cdot 100 \mathrm{~g}^{-1} \cdot \mathrm{min}^{-1}$, respectively). 


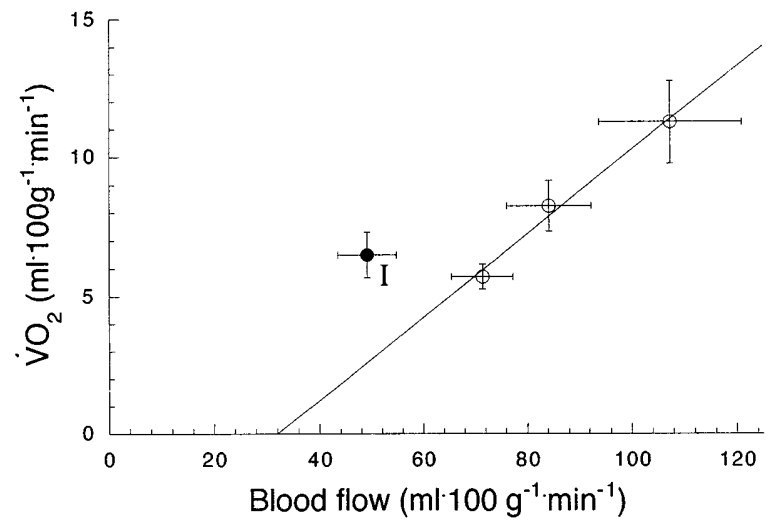

Fig. 2. Relationship between muscle $\dot{\mathrm{V}}_{2}$ and muscle blood flow for the 3 contraction periods at which blood flow was normal $(O)$ and I contraction period $(\bullet)$. Values are means $\pm \mathrm{SE}$. Correlation line is drawn from regression analysis (best fit) by using the 3 stimulation patterns with unrestricted blood flow.

\section{DISCUSSION}

This study demonstrated that when a moderate reduction of blood flow (to $46 \%$ of normal) was imposed on normally perfused, aerobically contracting skeletal muscle, force development was downregulated until the normal relationship of mitochondrial respiration and force production was restored. Muscle [PCr], [ATP], and lactate efflux were not altered significantly by the I condition compared with the same stimulation fre quency with normal blood flow. The insignificant changes in these variables during these partial ischemic conditions, even when force production and respiration were reduced by $50 \%$, was likely due to the blood flow reduction occurring after steady-state conditions of respiration and force in the contracting muscle had been established.

Relationship between $\dot{\mathrm{V}}_{2}$ and force production. Although the regulators of mitochondrial respiration in skel etal muscle have been well studied $(4,5,18,20,22)$ when $\mathrm{O}_{2}$ supply to the mitochondria is adequate, the manner in which mitochondrial respiration and muscle

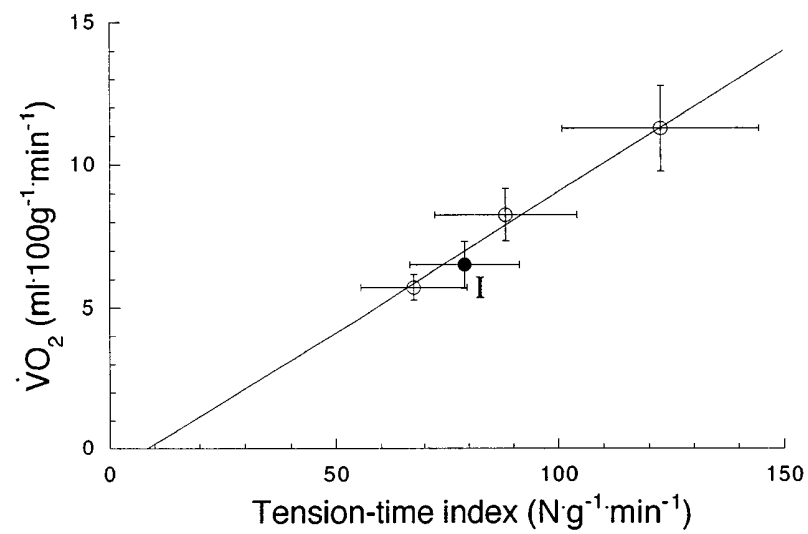

Fig. 3. Relationship between $\dot{\mathrm{V}}_{2}$ and tension-time index (index of work performed by muscle) for the 3 contraction periods at which blood flow was normal $(O)$ and I contraction period $(\bullet)$. Values are means $\pm \mathrm{SE}$. Correlation line is drawn from regression analysis (best fit) by using the 3 stimulation patterns with unrestricted blood flow.

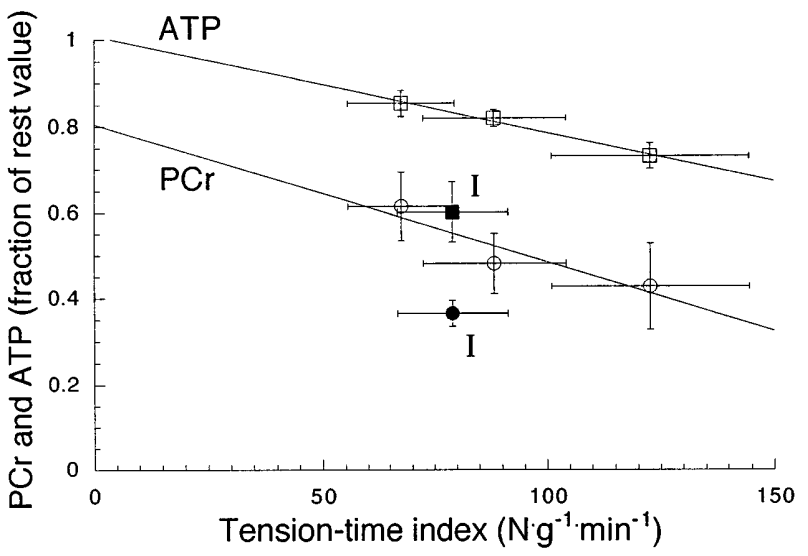

Fig. 4. Relationship between phosphocreatine $(\mathrm{PCr})(\bullet, 0 ; n=4)$ and $\operatorname{ATP}(\mathbf{\square}, \square ; n=5$; as fraction of rest values) and tension-time index (index of work performed by muscle) for the 3 contraction periods at which blood flow was normal $(\square, \bigcirc)$ and I contraction period $(\boldsymbol{\square}, \bullet)$. Values are means \pm SE. Correlation lines are only drawn from regression analysis (best fit) by using the 3 stimulation patterns with unrestricted blood flow.

force production are coupled when $\mathrm{O}_{2}$ availability is compromised has been less well documented. If nonoxidative sources for ATP rephosphorylation are recruited when $\mathrm{O}_{2}$ availability becomes rate limiting, then force production can be maintained to some degree by anaerobic glycolysis and PCr hydrolysis (substrate-level phosphorylation). However, continued high rates of substrate-level phosphorylation can lead to alterations in the intracellular environment that can ultimately result in cellular damage if the ATPase activity is not adjusted. It has been demonstrated that skel etal muscle $(12,16,17,31)$, especially muscle rich with highoxidative fibers, has some capacity to minimizeintracelIular disruption of homeostasis when $\mathrm{O}_{2}$ availability becomes limiting by simply downregulating force production (ATPase activity) to match flux through oxidative phosphorylation, with minimal activation of substrate-level phosphorylation. Although respiration and

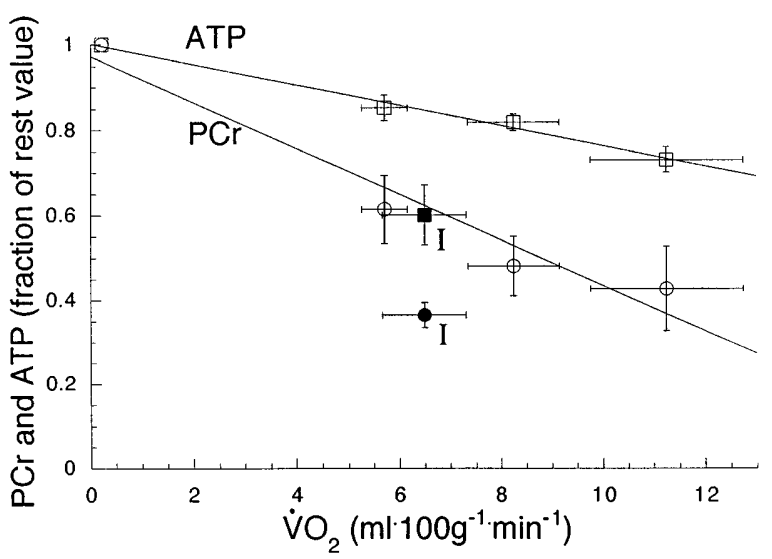

Fig. 5. Relationship between $\operatorname{PCr}(\bullet, 0 ; n=4)$ and $\operatorname{ATP}(\square, \square ; n=5$; as fraction of rest values) and $\mathrm{VO}_{2}$ for the 3 contraction periods at which blood flow was normal $(\square, 0)$ and I contraction period $(\square, \bullet)$. Values are means \pm SE. Correlation lines are only drawn from regression analysis (best fit) by using the 3 stimulation patterns with unrestricted blood flow. 
force production can be dramatically reduced under these conditions, there may only be minor changes in the intracellular concentrations of ATP, PCr, and lactate. This stategy maintains the "tight coupling" (10) of force production to mitochondrial respiration so that the $\mathrm{O}_{2}$ cost of the contractions remains constant.

The manner by which muscle can minimize intracelIular metabolic disruption, by downregulating ATPase activity to match the rate of oxidative phosphorylation, during conditions of partial ischemia is not well understood. Timmons et al. $(28,30)$ have recently demonstrated that activating the PDC before the initiation of an ischemic contractile period resulted in less depletion of muscle PCr and ATP, lower lactate accumulation, and enhanced subsequent force production compared with the control ischemic situation with no PDC activation. This indicates that when partial ischemia was imposed on contracting muscle at the onset of contractions, substrate availability for oxidative phosphorylation was inadequate and the reduced $\mathrm{O}_{2}$ availability was not the only factor determining subsequent muscle performance. The present study demonstrated that when $\mathrm{O}_{2}$ availability was reduced after normal steadystate conditions had been reached (fully aerobic contractions), the tight coupling of force production to respiration was maintained (see Fig. 3), as has been shown before in this highly oxidative muscle for moderate ischemia conditions $(2,6,8,9,26)$. Muscle [ATP], [PCr], and lactate efflux during the I condition were not significantly different from the values seen at the same stimulation intensity with normal blood flow. Timmons et al. (29) found muscle [PCr] and [ATP] to be significantly more depl eted (and found greater lactate accumulation) in contracting muscle when partial ischemia was imposed from the onset of contractions compared with a control condition at the same stimulation frequency but with normal blood flow. It is likely that in the present study, thelack of any significant differences in muscle [PCr], [ATP], and lactate efflux beween the I condition and the same stimulation with normal blood flow was due to the fact that the muscle was in a steady state of contractile activity, with all regulatory enyzmes fully activated, when the partial ischemia was induced. Our results, therefore, support the notion that prior activation of key regulatory enzymes before initiation of partial ischemia (30) may enhance cellular homeostasis and muscle function.

The question then arises as to the mechanism(s) by which, in the present study, the muscle reduced force development to the level at which the new steady-state force production was exactly matched to the rate of respiration that could be achieved from the limited amount of $\mathrm{O}_{2}$ available. There was no fall in peak developed force through the three normal blood flow contraction periods $(0.25,0.33$, and $0.5 \mathrm{~Hz})$, and the tension-time index increased in a linear manner with stimulation frequency (see Fig. 1B). However, after the reduction of muscle blood flow during the I condition, there was an immediate (within 2-3 contractions) fall in peak developed force until a new steady state was established within 3-4 min at a peak force development $65 \%$ of the value found before blood flow reduction. In this whole-muscle model, we cannot distinguish whether the reduction in force development at the onset of ischemia was a result of some fibers (possibly fibers with more "fast-twitch" characteristics) shutting down due to $\mathrm{O}_{2}$ deprivation (potentially from heterogeneous blood flow distribution) or whether all fibers simply reduced force development proportionally. The factors that cause the reduction in force development in contracting muscle over time, when stimulation patterns remain constant, are complex $(7,32,34)$. During contractions with ischemic blood flow reduction, there can be an accumulation of intracellular metabolites that can affect contractility and long-term muscle performance $(2,25)$. However, the immediate fall in force development in this muscle is primarily related to $\mathrm{O}_{2}$ availability (14), independent of blood flow. As discussed, there was little change in muscle $\mathrm{P}_{\mathrm{i}}$ concentration (inversely related to [PCr]) and lactate efflux during the I condition compared with the samestimulation frequency with normal blood flow. Increased levels of $\mathrm{H}^{+}$and $\mathrm{P}_{\mathrm{i}}$ have been implicated $(21,27,33,36)$ in the rapid development of high-intensity contractile fatigue by interfering with $\mathrm{Ca}^{2+}$ release, $\mathrm{Ca}^{2+}$ binding, or actomyosin binding (see Refs. 7, 32, and 34). It is likely that alterations in processes directly related to regulation of intracellular $\mathrm{Ca}^{2+}$ release were important in the reduction of force development during ischemia in the present study.

$\mathrm{O}_{2}$ regulation of metabolism. Although muscle [PCr] and [ATP] were not different between the I condition and the same stimulation frequency with normal blood flow, these variables were significantly reduced in the I condition compared with the $0.25-\mathrm{Hz}$ condition with normal blood flow. However, muscle $\mathrm{VO}_{2}$ and the tensiontime index were not significantly different (see Figs. 4 and 5) between the I condition and the $0.25-\mathrm{Hz}$ condition with normal blood flow. In addition to the reduced muscle [ATP] and [PCr] (and thereby increased $\mathrm{P}_{\mathrm{i}}$ ) at nearly equivalent rates of respiration $\left(\mathrm{VO}_{2} ; \mathrm{Fig} .5\right)$ and tension-time index (Fig. 4), the estimated [ATP]/ $[A D P]\left[P_{i}\right]$ ratio (ADP estimated from previous studies; 11,13 ) was reduced to $25 \%$ in the I condition compared with the value of this ratio in the $0.25-\mathrm{Hz}$ condition with normal blood flow. Thus, at the same rate of respiration and force output, the I condition had a significantly altered intracellular environment.

As has been demonstrated previously $(2,6,9,13,26)$, as blood flow was reduced in the present study the muscle was ableto extract a higher percentage of the $\mathrm{O}_{2}$ delivered by convective blood flow. A greater diffusion of $\mathrm{O}_{2}$ to the mitochondria (for a higher extraction) was likely accomplished by reductions in intracellular $\mathrm{PO}_{2}$. We have suggested previously $(11,12)$ that various substrates of oxidative phosphorylation may be modulated by intracellular $\mathrm{PO}_{2}$ or $\left[\mathrm{O}_{2}\right]$. Rumsey et al. (24) and Wilson et al. (35), using isolated mitochondria and isolated cells, have demonstrated that the regulators of oxidative phosphorylation are dependent on $\mathrm{O}_{2}$ at $\left[\mathrm{O}_{2}\right]$ 
values found in the physiological range and that there exists a wide range of $\mathrm{O}_{2}$ values that can influence the metabolic state of the cell. For a fixed rate of respiration, a higher concentration of the substrates of oxidative phosphorylation may be required as tissue $\mathrm{PO}_{2}$ falls. Although other factors related to the partial ischemia may have contributed to the very different intracellular environment at similar $\mathrm{VO}_{2}$ and force output, it is possible that differences in intracellular $\mathrm{PO}_{2}$ had a role in modulating these factors that regulate oxidative phosphorylation.

Conclusion. This study demonstrated that in contracting, highly oxidative muscle, a moderate blood flow reduction (with equivalent reductions in $\mathrm{O}_{2}$ availability) reduced the tension-time index to the point at which the normal relationship of the tension-time index and mitochondrial respiration was restored. With the blood flow reduction imposed after normal steadystate conditions of blood flow, respiration, and force output had already been achieved in a contractile period, there was little disruption of the intracellular environment as force was downregulated. This was likely a result of substrate availabilty and enzymatic processes being al ready adequately activated. In addition, the significant differences in muscle [ATP] and [PCr] between the I condition and the contraction period $(0.25 \mathrm{~Hz}$ with normal blood flow) that had a similar rate of respiration and tension-time index may in part have been due to an effect of reduced intracellular $\mathrm{PO}_{2}$ on the regulators of oxidative phosphorylation.

This research was supported by National Institutes of Health Grants AR-40155, AR-40342, and HL-17731 and by North Atlantic Treaty Organization Grant 950173.

Address for reprint requests: M. C. Hogan, Dept. of Medicine 0623-A, Univ. of California, San Diego, 9500 Gilman Dr., La J olla, CA 92093-0623 (E-mail: mchogan@ucsd.edu).

Received 6 November 1997; accepted in final form 3 F ebruary 1998.

\section{REFERENCES}

1. Barbee, R. W., W. N. Stainsby, and S. J . Chirtel. Dynamics of $\mathrm{O}_{2}, \mathrm{CO}_{2}$, lactate, and acid exchange during contractions and recovery. J . Appl. Physiol. 4: 1687-1692, 1983.

2. Barclay, J. K. A delivery-independent blood flow effect on skeletal muscle fatigue. J . Appl. Physiol. 61: 1084-1089, 1986.

3. Bergstrom, J . Percutaneous needle biopsy of skel etal muscle in physiological and clinical research. Scand. J . Clin. Lab. Invest. 35: 609-616, 1975.

4. Connett, R.J . Analysis of metabolic control: new insights using scaled creatine kinase model. Am. J . Physiol. 254 (Regulatory IntegrativeComp. Physiol. 23): R949-R959, 1988.

5. Connett, R. J ., and C. R. Honig. Regulation of $\dot{\mathrm{V}}_{2}$ in red muscle: do current biochemical hypotheses fit in vivo data? Am. J. Physiol. 256 (Regulatory Integrative Comp. Physiol. 25): R898-R906, 1989.

6. Dodd, S. L., S. K. Powers, E. Brooks, and M. P. Crawford. Effects of reduced $\mathrm{O}_{2}$ delivery with anemia, hypoxia, or ischemia on peak $\dot{\mathrm{V}}_{2}$ and force in skeletal muscle. J. Appl. Physiol. 74: 186-191, 1993

7. Fitts, R. H. Cellular mechanisms of muscular fatigue. Physiol. Rev. 74: 49-94, 1994.

8. Gladden, L. B., B. R. Maclntosh, and W. N. Stainsby. $\mathrm{O}_{2}$ uptake and developed tension during and after fatigue, curare block, and ischemia. J . Appl. Physiol. 45: 751- 756, 1978.
9. Gorman, M. W., J . K. Barclay, and H. V. Sparks. Effects of ischemia on $\mathrm{V}_{2}$, tension, and vascular resistance in contracting canine skeletal muscle. J . Appl. Physiol . 65: 1075-1081, 1988.

10. Hochachka, P. W. Metabolic suppression and oxygen availability. Can. J . Zool. 66: 152-158, 1988.

11. Hogan, M. C., P. G. Arthur, D. E. Bebout, P. W. Hochachka, and $\mathbf{P}$. D. Wagner. Role of $\mathrm{O}_{2}$ in regulating tissue respiration in dog muscle working in situ. J . Appl. Physiol. 73: 728- 736, 1992.

12. Hogan, M. C., S. S. Kurdak, and P. G. Arthur. Effect of gradual reduction in $\mathrm{O}_{2}$ delivery on intracellular homeostasis in contracting skeletal muscle. J. Appl. Physiol. 80: 1313-1321, 1996.

13. Hogan, M. C., S. Nioka, W. F. Brechue, and B. Chance. A 31P-NMR study of tissue respiration in working dog muscle during reduced $\mathrm{O}_{2}$ delivery conditions. J. Appl. Physiol. 73: 1662-1670, 1992.

14. Hogan, M. C., R. S. Richardson, and S. S. Kurdak. I nitial fall in skeletal muscle force devel opment during ischemia is related to oxygen availability. J . Appl. Physiol. 77: 2380-2384, 1994.

15. Hogan, M. C., and H. G. Welch. Effect of altered arterial $\mathrm{O}_{2}$ tensions on muscle metabolism in dog skeletal muscle during fatiguing work. Am. J. Physiol. 251 (Cell Physiol. 20): C216C222, 1986.

16. Ito, B. R. Gradual onset of myocardial ischemia results in reduced myocardial infarction: association with reduced contractile function and metabolic downregulation. Circulation 91: 2058-2070, 1995.

17. Li, G. C., J . A. Vasquez, K. P. Gallagher, and B. R. Luchesi. Myocardial protection with preconditioning. Circulation 82: 609619, 1990.

18. Mahler, M. First-order kinetics of muscle oxygen consumption, and an equivalent proportionality between $\mathrm{QO}_{2}$ and phosphorylcreatinelevel. J . Gen. Physiol. 86: 135- 165, 1985.

19. Maxwell, L. C., J . K. Barclay, D. E. Mohrman, and J . A. Faulkner. Physiological characteristics of skeletal muscles of dogs and cats. Am. J. Physiol. 233 (Cell Physiol. 2): C14-C18, 1977.

20. McMillan, J . B., and D. F. Pauly. Control of mitochondrial respiration in muscle. Mol. Cell. Biochem. 81: 121-129, 1988.

21. Metzger, J . M., and R. H. Fitts. Role of intracellular $\mathrm{pH}$ in muscle fatigue. J . Appl. Physiol. 62: 1392-1397, 1987.

22. Meyer, R. A. A linear model of muscle respiration explains monoexponential phosphocreatine changes. Am. J . Physiol. 254 (Cell Physiol. 23): C548-C553, 1988.

23. Motterlini, R., M. Samaja, M. Tarantola, R. Micheletti, and G. Bianchi. Functional and metabolic effects of propionyl-Lcarnitine in the isolated perfused hypertrophied rat heart. Mol. Cell. Biochem. 116: 139- 145, 1992.

24. Rumsey, W. L., C. Schlosser, E. M. Nuutinen, M. Robiolio, and D. F. Wilson. Cellular energetics and the oxygen dependence of respiration in cardiac myocytes isolated from adult rat. J . Biol. Chem. 265: 15392-15399, 1990.

25. Samaja, M., S. Casalini, S. Allibardi, A. Corno, and S. L. Chierchia. Regulation of bioenergetics in $\mathrm{O}_{2}$-limited isolated rat hearts. J . Appl. Physiol. 77: 2530-2536, 1994.

26. Stainsby, W. N., W. F. Brechue, D. M. O'Drobinak, and J . K. Barclay. Effects of ischemic and hypoxic hypoxia on $\mathrm{V}_{2}$ and lactic acid output during tetanic contractions. J . Appl. Physiol. 68: 574- 579, 1990.

27. Thompson, L. V., and R. H. Fitts. Muscle fatigue in the frog semitendinosus: role of the high-energy phosphates and $\mathrm{P}_{\mathrm{i}} . \mathrm{Am}$. J . Physiol. 263 (Cell Physiol. 32): C803-C809, 1992.

28. Timmons, J . A., S. M. Poucher, D. Constantin-Teodosiu, I. A. Macdonald, and P. L. Greenhaff. Metabolic responses from rest to steady state determine contractile function in ischemic skeletal muscle. Am. J. Physiol. 273 (Endocrinol. Metab. 36): E233-E238, 1997.

29. Timmons, J . A., S. M. Poucher, D. Constantin-Teodosiu, V. Worral, I. A. Macdonald, and P. L. Greenhaff. Increased acetyl group availability enhances contractile function of canine 
skeletal muscle during ischemia. J . Clin. Invest. 97: 879-883, 1996.

30. Timmons, J . A., S. M. Poucher, D. Constantin-Teodosiu, V. Worral, I. A. Macdonald, and P. L. Greenhaff. Metabolic responses of canine gracilis muscle during contraction with partial ischemia. Am. J. Physiol. 270 (Endocrinol. Metab. 33): E400-E406, 1996.

31. Walker, D. M., and D. M. Yellon. Ischaemic preconditioning: from mechanisms to exploitation. Cardiovasc. Res. 26: 734- 739, 1992.

32. Westerblad, H., J . A. Lee, J . Lannergren, and D. G. Allen. Cellular mechanisms of fatigue in skeletal muscle. Am. J. Physiol. 261 (Cell Physiol. 30): C195- C209, 1991.
33. Wilkie, D. R. Muscular fatigue: effects of hydrogen ions and inorganic phosphate. Federation Proc. 45: 2921-2923, 1986.

34. Williams, J . H., and G. A. Klug. Calcium exchange hypothesis of skeletal muscle fatigue: a brief review. Muscle Nerve 18: 421-434, 1995.

35. Wilson, D. F., M. E recinska, C. Drown, and I. A. Silver. The oxygen dependence of cellular energy metabolism. Arch. Biochem. Biophys. 195: 485-493, 1979.

36. Wilson, J . R., K. K. McCully, D. M. Mancini, B. Boden, and B. Chance. Relationship of muscular fatigue to $\mathrm{pH}$ and diprotonated $P_{i}$ in humans: a ${ }^{31}$ P-NMR study. J. Appl. Physiol. 64: 2333-2339, 1988.

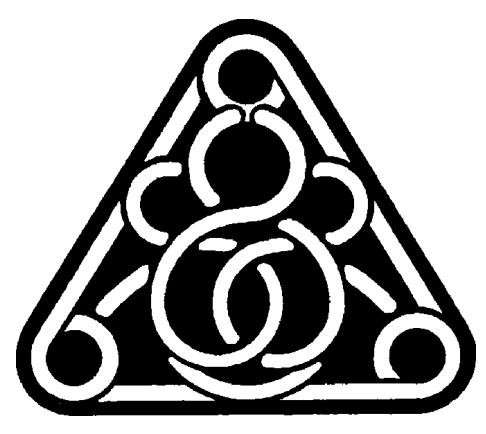

